See Article page 1.

\section{Commentary: Thoracic endovascular aortic repair involving landing zone 0: Ready for take-off?}

\author{
Thierry Carrel, MD, ${ }^{a}$ and Martin Czerny, $\mathrm{MD}^{\mathrm{b}}$
}

The optimal management of aneurysms located in the proximal or the middle aortic arch with thoracic endovascular aortic repair (TEVAR) devices remains a matter of debate. Although increasing evidence has been accumulated for zones 2 and 3, only a few small series and case reports with handmade devices and specially designed branched stent grafts from industrial partners such as Gore (Flagstaff, Ariz) have been published to date. ${ }^{1-3}$

Among the reasons for this, such as technical difficulties in providing a customized multibranched industrial device, also may be the rarity of saccular and fusiform aneurysms located in the aortic arch and strictly limited to this portion of the thoracic aorta. In that sense, Dake and colleagues ${ }^{4}$ must be congratulated for their efforts with this singleside branch graft designed to facilitate aortic coverage proximal to the innominate or left carotid artery. However, this technique still requires some extensive surgery at the level of the supra-aortic branches and is probably most appropriate for treating a highly selected subgroup of patients with ideal anatomy. Classical surgery favors orthotopic reconstruction in the majority of cases, and the current notion in the endovascular world is that approaches that

From the a Department of Cardiac Surgery, University Hospital Zürich, Zürich, Switzerland; and ${ }^{\mathrm{b}}$ Department of Cardiovascular Surgery, University Heart Center, Freiburg-Bad Krozingen, Germany.

Disclosures: Dr Czerny serves as a consultant for Terumo Aortic and Medtronic, has received speaking honoraria from Cryolife-Jotec and Bentley, and is shareholder of TEVAR Ltd. Dr Carrel has reported no conflicts of interest.

The Journal policy requires editors and reviewers to disclose conflicts of interest and to decline handling or reviewing manuscripts for which they may have a conflict of interest. The editors and reviewers of this article have no conflicts of interest.

Received for publication Feb 17, 2021; revisions received Feb 17, 2021; accepted for publication Feb 22, 2021; available ahead of print March 2, 2021.

Address for reprints: Thierry Carrel, MD, Department of Cardiac Surgery, University Hospital, Rämistrasse 100, CH-8091 Zürich, Switzerland (E-mail: thierry.carrel@ usz.ch).

JTCVS Techniques 2021;7:9-10

2666-2507

Copyright (C) 2021 The Authors. Published by Elsevier Inc. on behalf of The American Association for Thoracic Surgery. This is an open access article under the CC BY-NCND license (http://creativecommons.org/licenses/by-nc-nd/4.0/).

https://doi.org/10.1016/j.xjtc.2021.02.045
Check for updates

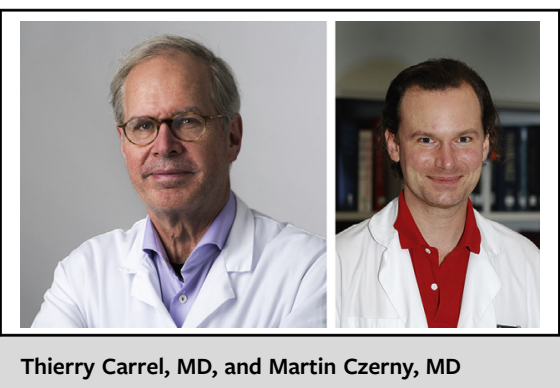

CENTRAL MESSAGE

Thoracic endovascular aortic

repair with landing zone $\mathrm{O}$ is a

promising option, but substantial

efforts are still necessary before

recommending the procedure

for a majority of patients with

aortic arch lesions.

mimic nature, with 2 or even 3 branches, will most likely be superior in the long run. ${ }^{5}$

Two out of the authors' 9 patients experienced cerebrovascular events not only during the procedure, but also at the midterm follow-up. The reason for these periinterventional adverse events may be atherosclerotic changes, but it is disturbing that the same patients experienced repeat stroke in the midterm, after the aortic arch had been excluded from circulation. The images shared in this report should highlight the importance of taking every effort to maximize our understanding of the underlying disease, given recent evidence showing that postdissection aneurysmal formation is associated with the lowest incidence of stroke following endovascular aortic arch repair, whereas atherosclerotic pathologies, as shown here, are associated with the highest risk, most likely related to wire manipulation and consecutive detachment of atherosclerotic debris.

This is one of the main reasons why patients with atherosclerotic etiology (eg, penetrating atherosclerotic ulcers) will eventually benefit more from open surgery than from transcatheter techniques. Remote cannulation, systemic cooling and addressing the disease during a phase of lower body hypothermic circulatory arrest and selective antegrade cerebral perfusion is the better option to minimize the remaining risk of debris detachment and embolization. ${ }^{6}$

Another point that should be highlighted is the fact that 3 patients $(30 \%)$ developed endoleaks in the midterm. A 
longer follow-up is needed to evaluate the need to treat these endoleaks. The development of most endoleaks can be anticipated during planning, and understanding the underlying disease, providing adequate landing zones, and respecting the anatomy are the most important components the ensure for success and avoidance of late secondary surgical conversions. ${ }^{7}$

Patient characteristics included a mean age of 72 years and mean body mass index of only 25 . Considered with their cardiovascular risk factors, these patients do not seem to have been neither very old nor very sick. One patient had undergone previous aortic surgery. The images provided for demonstration are those of a 62-year-old patient. Decision making regarding the operative approach, open surgery or endovascular repair, includes many components, the most critical being suitable anatomy and a nonatherosclerotic underlying disease. This is particularly true when opting for TEVAR, for the aforementioned reasons. ${ }^{8}$ Thus, the importance of treating such patients in aortic centers, where all treatment options are available under one umbrella and where objective decisions are made by both surgical and endovascular teams, cannot be overemphasized.

Finally, neurologic outcome remains the Achilles heel of all therapeutic approaches for lesions involving the aortic arch. The success or failure of a certain strategy over another will be based on evaluation of neurologic outcome. This report elegantly shows us how a major component of the future of aortic medicine will look, but also stresses that much remains to be done at every level to provide satisfying results: a clear-cut indication to proceed with a treatment, the choice of the best possible modality, the establishment of a treatment concept, the performance of the procedure, and, finally, long-term surveillance after a successful therapy.

\section{References}

1. Patel HJ, Dake MD, Bavaria JE, Singh MJ, Filinger M, Fischbein MP, et al. Branched endovascular therapy of the distal aortic arch: preliminary results of the feasibility multicenter trial of the Gore thoracic branch endoprosthesis. Ann Thorac Surg. 2016;102:1190-8.

2. Spear R, Haulon S, Ohki T, Tsilimparis N, Kanaoka Y, Milne CPE, et al. Editor's choice-subsequent results for arch aneurysm repair with inner branched endografts. Eur J Vasc Endovasc Surg. 2016;51:380-5.

3. Czerny M, Rylski B, Morlock J, Schröfel H, Beyersdorf F, Saint Lebes B, et al. Orthotopic branched endovascular aortic arch repair in patients who cannot undergo classical surgery. Eur J Cardiothorac Surg. 2018;53:1007-12.

4. Dake MD, Bavaria JE, Singh MJ, Oderich G, Filinger M, Fischbein MP, et al. Management of arch aneurysms with a single-branch thoracic endograft in zone 0. J Thorac Cardiovasc Surg Tech. 2021;7:1-6.

5. Beckmann E, Martens A, Korte W, Kaufeld T, Krueger H, Haverich A, et al. Open total arch replacement with trifurcated graft and frozen elephant trunk. Ann Cardiothorac Surg. 2020;9:170-7.

6. Kreibich M, Kremer J, Vötsch A, Berger T, Farag M, Winkler A, et al. Multicentre experience with the frozen elephant trunk technique to treat penetrating aortic ulcers involving the aortic arch. Eur J Cardiothorac Surg. February 1, 2021; https:// doi.org/10.1093/ejcts/ezaa480 [Epub ahead of print].

7. Grabenwoger M, Fleck T, Ehrlich M, Czerny M, Hutschala D, Schoder M, et al. Secondary surgical interventions after endovascular stent-grafting of the thoracic aorta. Eur J Cardiothorac Surg. 2004;26:608-13.

8. Verscheure D, Haulon S, Tsilimparis N, Resch T, Wanhainen A, Mani K, et al. Endovascular treatment of post type A chronic aortic arch dissection with a branched endograft: early results from a retrospective international multicenter study. Ann Surg. April 8, 2019; https://doi.org/10.1097/SLA.0000000000003310 [Epub ahead of print]. 